2019 in Synthese

https://doi.org/10.1007/s11229-019-02116-w

\title{
Towards a dual process epistemology of imagination
}

\author{
Michael T. Stuart \\ Department of Philosophy, University of Geneva, Rue de Candolle 2, 1211 Geneva, Switzerland \\ mike.stuart.post@gmail.com
}

\begin{abstract}
Sometimes we learn through the use of imagination. The epistemology of imagination asks how this is possible. One barrier to progress on this question has been a lack of agreement on how to characterize imagination; for example, is imagination a mental state, ability, character trait, or cognitive process? This paper argues that we should characterize imagination as a cognitive ability, exercises of which are cognitive processes. Following dual process theories of cognition developed in cognitive science, the set of imaginative processes is then divided into two kinds: one that is unconscious, uncontrolled, and effortless, and another that is conscious, controlled, and effortful. This paper outlines the different epistemological strengths and weaknesses of the two kinds of imaginative process, and argues that a dual process model of imagination helpfully resolves or clarifies issues in the epistemology of imagination and the closely related epistemology of thought experiments.
\end{abstract}

Keywords: Epistemology of imagination - Thought experiments - Scientific imagination · Dual process model of cognition

\section{Imagination has epistemological import}

The imagination is one of the most distinctive and philosophically interesting cognitive powers that humans possess. It is also one of the least well understood. Failure to account for its strengths and weaknesses guarantees the incompleteness of any would-be epistemology of human reasoning. ${ }^{1}$ The literature relevant for developing an epistemology of imagination is complex. There is valuable work done by historians, sociologists, philosophers and cognitive scientists. ${ }^{2}$ Yet, the "epistemology of imagination is only beginning to emerge as a topic in its

\footnotetext{
${ }^{1}$ One might doubt the power of imagination to produce knowledge, although most philosophers writing on the topic now take this for granted (including, e.g., most of the entries in Kind and Kung 2016 and Stuart et al. 2018a; see also Wansing 2017, p. 2843). A weaker objection would be that imagination is not a "proper" object of epistemological study because it is not a "fundamental" source of knowledge. This argument, however, can be run equally on experiments, models, instruments, computer simulations, and other tools of science. It doesn't seem reasonable (to me, at least) to deny the progress made by epistemologists on the functioning of these tools just to avoid the possibility of epistemology of imagination.

${ }^{2}$ Recent years have seen an "explosion of philosophical interest" in the imagination (Funkhouser and Spaulding 2009, p. 291). Seminal contributions include Byrne (2005), Currie and Ravenscroft (2002), McGinn (2004), Nichols (2006), Nichols and Stich (2003), Walton (1990), Kind and Kung (2016) and Kind (2016).
} 
own right, and no survey of it yet exists" (Strohminger 2016). ${ }^{3}$ Two obstacles to fruitful discourse have been the lack of an accepted general characterization of imagination, and the lack of a discussion regarding the form that epistemology of imagination should take (e.g., should it be done traditionally, formally, like virtue epistemology, or in some other way?).

The first obstacle arises from the fact that imagination is discussed by many different disciplines, with each discipline requiring slightly different things from the concept, and it is unclear whether or how these different characterizations could or should be combined. ${ }^{4}$ To circumvent this, philosophers often turn from imagination in general to certain kinds of imagination; e.g., sensory versus cognitive (McGinn 2004), propositional versus non-propositional (Walton 1990; Yablo 1993), enactment versus suppositional (Goldman 2006), and dramatic versus hypothetical (Moran 2017, pp. 24-25). Likewise, cognitive scientists break up the concept of imagination into processes that are more amenable to empirical study, e.g., counterfactual reasoning (e.g., Byrne 2005; Kahneman and Miller 1986; Mandel et al. 2005), mental simulation (e.g., Khemlani et al. 2013; Markman et al. 2009), mental imagery (e.g., Kosslyn 1994; Kosslyn et al. 2006; Pylyshyn 2002), narrative reasoning (Weisberg et al. 2013) and mental time travel (Botzung et al. 2008; Suddendorf et al. 2009; Suddendorf and Busby 2003), as well as memory, dreaming, and hallucination.

It's good to let a thousand flowers bloom, but not enough effort has been made to see how the philosophers' distinctions relate to the processes identified by cognitive scientists. Until this is done, philosophers and cognitive scientists will have difficulty pooling their resources to understand the nature of imagination. Such cooperation is important for identifying the epistemological strengths and weaknesses of the imagination and explaining why some uses of imagination are epistemically efficacious while others are not. The account to be presented attempts to make progress in this direction while remaining consistent with all current definitions of imagination. It combines three perspectives on imagination that form one framework. The first perspective takes imagination to be a cognitive ability. The other two are different ways of exercising that ability, corresponding to the two processes in the dual process model of cognition.

The idea of applying a dual process model of cognition to imagination is not new: hints can be found in philosophy by Arcangeli (2017), Gendler (2007), Walton (1990), and Williamson (2016), and in cognitive science by Evans and Frankish (2009). This paper aims to install this idea on a stronger philosophical foundation, develop it, and then put it to work in epistemology of imagination.

\footnotetext{
${ }^{3}$ This is also true for scientific imagination, which will be the main focus of Sects. 4.1-4.3 (McAllister 2013b, see also Meynell 2018, p. 508), though see Hadamard (1996), Holton (1998), Brown (2011), Frappier et al. (2013), Sorensen (1992), Buzzoni (2008), Gendler (2000), Nersessian (2008), Stuart (2017), Stuart et al. (2018a) and Clement $(2008,2009)$.

${ }^{4}$ Strawson writes, 'The uses, and applications, of the terms 'image,' 'imagine,' 'imagination,' and so forth make up a very diverse and scattered family. Even this image of a family seems too definite. It would be a matter of more than difficulty to identify and list the family's members, let alone their relations of parenthood and cousinhood" (Strawson 1970, p. 31). For other expressions of this difficulty, see McGinn (2004, pp. 1-2), Kind and Kung (2016, p. 3) and Walton (1990, p. 19).
} 
To do this, we must first overcome the second obstacle mentioned above, which is our lack of any detailed explication of what "epistemology of imagination" refers to, and how it should be done. This is important given the state of the field and also because it will serve to constrain the framework to be presented.

\section{Epistemology of imagination}

To do epistemology, we study the epistemological properties of certain objects. The different ways of doing epistemology vary according to the properties deemed epistemological, and the kinds of objects which instantiate those properties. Candidate epistemological properties include knowledge, understanding, truth, justification, evidence, and explanation. Possible bearers of epistemological properties include mental states, character traits, and processes. The different ways of doing epistemology correspond to the combinations of properties and objects that we take to be explanatorily fundamental. ${ }^{5}$ In other words, an epistemologist who thinks the mental state of knowledge is explanatorily fundamental has a different epistemological strategy than someone who privileges character traits that enable understanding.

In this section, I am not going to focus on the different epistemological properties; I will follow the literature in focusing on knowledge. ${ }^{6}$ I will, however, briefly discuss three possible bearers of epistemological properties, namely, mental states, character traits and processes.

If we focus on mental states as the bearers of epistemological properties, we investigate which epistemological properties apply to which mental states (commonly thought of as propositional attitudes), and why. For example, in modal epistemology we identify a class of mental state (viz, belief in modal propositions) and then ask which epistemological properties (justification, truth, etc.) we can ascribe to such states, and what justifies the ascription of those properties.

If instead of mental states we focus on character traits as the bearers of epistemological properties, we are doing virtue (or trait-based) epistemology. For example, in Engel's (2016) paper "Epistemology of Stupidity," Engel raises a way that agents can be (i.e., stupid) in order to analyze this trait and discuss its epistemological impact on the agents who possess it.

Finally, if we focus on processes as the bearers of epistemological properties, we are doing what might be called process-based epistemology. Epistemology in this sense includes the epistemologies of perception, experiment, and computer simulation.

We can do epistemology of imagination using each of these three strategies. According to the first, we characterize imagination as a mental state, and focus on what justifies the ascription of certain epistemological properties to those states. According to the second, we treat imagination as a character trait (imaginativeness), and focus on how it affects the epistemological standing of agents that possess it. In the third, we treat imagination as a process, single out its epistemic uses,

\footnotetext{
${ }^{5}$ Not all combinations of properties and property-bearers are possible explananda for current epistemology. For example, while epistemologists discuss true propositions and reliable processes, it is not clear how they could discuss true character traits. I thank an anonymous reviewer for this point.

${ }^{6}$ For understanding see Stuart (2016a, 2018).
} 
and focus on what enables these processes to obtain certain epistemological properties (e.g., reliability) when they do.

Each of the three epistemological strategies can inform the others. Knowing which agents are epistemologically virtuous might inform us about which processes and mental states are epistemologically good (namely, those processes that epistemologically virtuous agents tend to perform, and those mental states that epistemologically virtuous agents tend to have). And likewise if we begin with mental states or if we begin with processes. Which unit of epistemological explanation we take as fundamental will rely on meta-epistemological considerations. I will now briefly present some such considerations in favour of pursuing epistemology of imagination in the process-based sense.

Most philosophers working on imagination take it to be a mental state. Indeed, "it is an axiom of contemporary theories of imagining that states of imagination are mental states with propositional contents" (Kieran and McIver Lopes 2003a, p. 9; see the entries in Kieran and McIver Lopes 2003b; Kind and Kung 2016; Nichols 2006). Nevertheless, epistemology of imagination as a mental state is complicated by the fact that we want to know how we gain knowledge through imagination, which already implies that we are concerned with imagination as a process. For example, we might draw conclusions that we take to be informative about the world from certain imaginings, as we do from idealized models in science. But this line of argument highlights the shift from considering the epistemological qualities of mental states, to considering the epistemological qualities of a process of inference-making from mental states. If we are to do state-based epistemology of imagination, that is, if we are to find out how imagined mental states come to be known or play a role in gaining new knowledge, I suggest that the imagined content must figure somehow into an argument, inference, or other kind of process. This is already implicit in some authors. For example, Nichols and Stich (2000) are interested in propositional imagination (a mental state), but when they turn to epistemological concerns they introduce an inference mechanism (called the "Script Elaborator") to explain how we draw correct conclusions from imagined contents (2000, p. 35).

Here, the epistemological heavy lifting is done by a process. This is not to say that it is impossible to investigate the epistemological properties of imaginative mental states independently of cognitive processes, but merely that epistemology of imagination seems necessarily to be interested also in the question of processes.

To inquire epistemologically into imaginativeness as a character trait, a virtue epistemologist might begin by postulating a spectrum of strengths of imaginativeness. Someone who is too imaginative imagines irrelevant things at the slightest provocation in unnecessarily sharp detail, for extended periods of time. Someone who is not sufficiently imaginative will fail to look for new avenues of inquiry and will have trouble making epistemic progress as soon as their usual methods cease to produce results. What we want epistemologically from imaginative agents is for them to imagine the right amount, when appropriate. But to go further and say what it is about the right amount of imaginativeness that is epistemologically laudable, we have to look at particular cases (actual or possible) where the agent imagined "properly," and ask what it is about those proper uses of imagination that led the agent to epistemic success. Proper exercises of the virtue of imaginativeness (like proper uses of courage and charity) will be actions. Since 
actions are a kind of process, we are ushered once more toward epistemology of imagination in the process-based sense.

To do epistemology of imagination in the process-based sense, we need to know what kind of process imagination is. Perhaps one day imagination will be programmed into computers, at which point we could characterize it as a material or formal process (see Stuart forthcoming). Or perhaps neuroscientists will reduce imagination to neurological or chemical processes. Given the current state of research, however, it seems best to understand imagination as a cognitive process, like inferring, remembering, etc. This is a natural way to bring together the work on imagination in cognitive science and philosophy.

The dual process model of cognition claims that cognitive processes are of (at least) two different kinds. I will apply the dual process distinction to imaginative processes in the next section. First, we must roughly delimit the general set of cognitive processes that are imaginative in a way that captures current conceptions of imagination in both philosophy and cognitive science. I think the best way to do this is to portray imagination as a cognitive ability, the exercises of which are processes. What I propose is not a definition, but a schema that generates definitions, depending on how the three main parameters of the schema are spelled out. Here is the schema:

Imagination is the ability to interact cognitively with objects not present to sensory experience.

I want to emphasize that this is not meant as a definition of imagination, but as a schema that can be filled in to produce definitions of imagination. ${ }^{7}$ It works by specifying its three parameters: cognitive interaction (mode), objects (content), and not present to sensory experience (the part of the mode that qualifies something as imaginative). ${ }^{8}$

\footnotetext{
${ }^{7}$ I think it is tempting to read this schema as a definition because it resembles many existing definitions of imagination. Compare the Oxford English Dictionary, which defines imagination as "having an image or concept of something not presently perceived" (cited in Stevenson 2003, p. 238). Many of Leslie Stevenson's "Twelve Conceptions of Imagination" (2003) also fit this schema: specifically (1a-d), (4a, b), (5), and (6). This is also true for the characterizations we find in Aquinas's Summa Theologica I 85 ad 3, Kant's Anthropology from a Pragmatic Point of View §15, Ak. VII: 153, and Hume's Treatise (e.g., I.iii.ix). Among contemporary philosophers, McAllister (2013a) characterizes imagination as the mental capacity to conceive states of affairs not previously experienced. Similarly, those writing on mental imagery, e.g., Kosslyn et al. (1995, p. 1335), often make claims like "Visual mental imagery is 'seeing' in the absence of the appropriate immediate sensory input, auditory mental imagery is 'hearing' in the absence of the immediate sensory input, and so on"; Pearson et al. (2015) note that "we use the term 'mental imagery' to refer to representations [...] of sensory information without a direct external stimulus" and Richardson: "Mental imagery refers to all those quasi-sensory or quasi-perceptual experiences [...] which exist for us in the absence of those stimulus conditions that are known to produce their genuine sensory or perceptual counterparts, and which may be expected to have different consequences from their sensory or perceptual counterparts" (1969, pp. 2-3). Several of these examples are taken from Nanay (2015), who also holds a similar characterization.

${ }^{8}$ Notice that this schema does not include anything about a distinctive phenomenology for imagination. Some philosophers claim that imagination has a special phenomenal character (e.g., you know that you are imagining rather than perceiving because the experience is different). I think phenomenology can be useful in contrasting different mental states, and therefore it might be that phenomenology should be a factor for distinguishing between imaginative and non-imaginative mental states. But this schema concerns an ability, and abilities themselves do not have phenomenal character. While the ability to imagine might reliably produce mental states with a unique
} 
By cognitive interaction we might mean (re)presenting, simulating (as in running a mental model), manipulating (as in spatially manipulating a shape, manipulating a scenario or logically manipulating a proposition), creating, or something else. Since this notion can be as broad or constrained as we like, many characterizations of imagination are possible, from simulative model-based reasoning, to representational and recreational accounts, imagistic recombination, and first person perspective-taking. We can also constrain the mode to include or exclude processes like memory or dreaming.

By objects we might mean physical objects, actions, states of affairs, propositions, images, or something else. This parameter defines the content of imagination, and by specifying it, we can restrict our characterization of imagination to, e.g., propositional imagination (imagine that your father is walking down a street), objectual imagination (imagine your father), or active imagination (imagine walking). It may turn out that only one kind of object is relevant for epistemology, e.g., perhaps only propositional content is relevant. But this is an open question in epistemology of imagination, and in any case, the schema is meant to produce all definitions of imagination, not just those that are epistemologically relevant. ${ }^{9}$

Finally, by not present to sensory experience we might mean not currently being senseexperienced, never having been sense-experienced, containing at least one element/aspect of which is not currently being sense-experienced, containing at least one element/aspect of which was never sense-experienced, or something else. This qualifier (in however strong a form) is meant to capture what is considered by most authors in the literature a necessary component of imagination, namely that imagination must somehow diverge from current sensory experience.

By using the definition-schema we ensure that all definitions of imagination are included in what follows, without necessarily approving of any one in particular. All specifications of the schema will be consistent with treating imagination as a trait, process or state: imaginativeness as a trait is the disposition to exercise the ability to imagine; imagination as a process is an exercise of the ability to imagine; and imagination as a mental state is an intermediate step or final outcome of such an exercise, or if we prefer, the abstract (usually functional) portrayal of the relation between the agent who performs any such exercise and the object of their imagining.

We can now add the dual process model to the schema.

\section{The dual process model of imagination as a framework for epistemology of imagination}

The dual process model is the idea that there are at least two kinds of human cognitive process (see Evans and Over 1996; Frankish 2004; Kahneman et al. 1982; Sloman 1996, 2002; Stanovich 1999). Or put another way, claims about dual processes "are not so much claims about how many processes there are, but claims about how many processes there aren't. And the claim is

phenomenal character, I am not sure this is true, so I won't rely on arguments from phenomenal character at this point. I thank an anonymous reviewer for pressing me on this.

${ }^{9} \mathrm{I}$ thank an anonymous reviewer for pointing this out. 
this: There aren't one" (Gilbert 1999, pp. 3-4, quoted in Gendler 2007, p. 75). Certainly, not all cognitive processes require the same amount of cognitive effort. And not all processes are equally accessible to introspection. The next insight is that variables like these appear to arrange themselves on different sides of a single divide. Jonathan Evans, one of the originators of this theory in its modern form, organizes some of the important variables as in Table 1.

The distinction between these two kinds of cognitive process has been fruitful in work on memory (Atkinson and Juola 1973, 1974; Hintzman and Curran 1994; Jacoby 1991; Jacoby and Dallas 1981; Mandler 1980), brain lesion studies (Aggleton et al. 2005; Cipolotti et al. 2006; Fortin et al. 2004; Yonelinas et al. 2002) and many other topics. The differences between the processes are individuated functionally or phenomenologically, and are not necessarily meant to correspond to divisions in brain parts or brain activities.

There is debate concerning whether these variables do really come apart so neatly, or whether we need more than two types of process to account for human cognition. Evans and Frankish (2009) present an overview of these challenges, and new challenges emerge regularly. For example, the model has recently been criticized by Westra (2017) on the grounds that "fast" cognition can be flexible, and flexibility is supposed to be a trait associated with slow processes, not fast ones.

\begin{tabular}{|l|l|}
\hline System 1 & System 2 \\
\hline Unconscious & Conscious \\
\hline Automatic & Controlled \\
\hline Low effort & High effort \\
\hline Rapid & Slow \\
\hline High capacity & Low capacity \\
\hline Default process & Inhibitory \\
\hline Holistic, perceptual & Analytic, reflective \\
\hline Evolutionarily old & Evolutionarily recent \\
\hline Evolutionary rationality & Individual rationality \\
\hline Shared with animals & Uniquely human \\
\hline
\end{tabular}

Table 1. Some of the differences between the two kinds of cognitive process (for the full list, see Evans 2008, p. 257)

The most common worry seems to be that the dual process model is trivial: since each cognitive process admits of the distinction, it becomes part of the definition of "cognitive process," rather than a falsifiable hypothesis about cognition. This might be a fair criticism against the way that some cognitive scientists understand the model, but it is not effective against the use of this account for epistemological purposes. We want a framework for discussing the epistemology of imagination at a level that is general enough for both philosophers and cognitive scientists to agree on, and this works especially well if the dual process distinction is a constitutive a priori principle for research into cognitive processes rather than a falsifiable empirical claim. And any claims associated with the model that do stand on shaky empirical ground, like whether flexibility or speed are system 1 or system 2 processes (Westra's concern, mentioned above), can be left behind. We are here concerned only with the first three rows of Evans's table: accessibility to consciousness, degree of control, and effort. These are common to all 
instantiations of the dual process model, they are among the distinctions made in what have been claimed as early ancestors of the theory, and they are sufficiently accessible to introspection such that it is extremely unlikely they will turn out to be false. E.g., it is difficult to see how unconscious processes might actually have been conscious all along, etc. ${ }^{10}$

We can now formulate a tripartite characterization of imagination that incorporates the dual process model. Call any specification of the definition-schema, "imaginationo." Whatever the details of the specification, imagination ${ }_{0}$ will be an ability that we have to imagine. Call "imagination 1 " the unconscious, uncontrolled, effortless cognitive interaction with objects not currently present to sensory experience, where "cognitive interaction," "objects" and "not currently present to sensory experience" are defined in accordance with the imagination 0 that we are currently using.

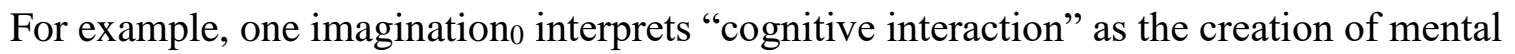
images, and takes the content of those images to be the objects of imagination, and requires that the objects of imagination contain aspects which are not present to the senses. In this case,

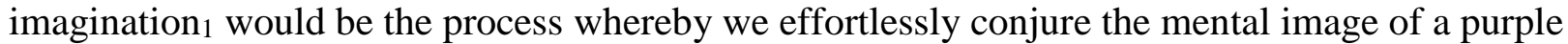
elephant when one is mentioned, even when we are explicitly trying to avoid doing this.

Call "imagination," the controlled, effortful and conscious cognitive interaction with objects not currently present to sensory experience, again, where the parameters of the schema are

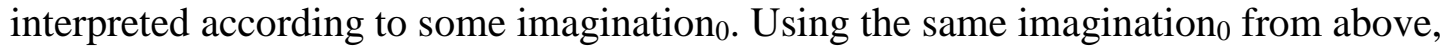

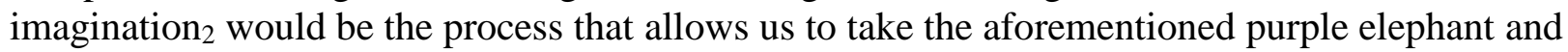
make it juggle while riding a unicycle down Fifth Avenue. In a particular use of this sort of imagination, there will be a beginning, end, and steps in between. The process is consciously accessible to us, and requires some effort to perform.

The distinction between imagination in $_{0}$ on the one hand, and imagination and $_{2}$ on the other, is a categorical distinction between an ability and uses of that ability (processes). However, the distinction between imagination ${ }_{1}$ and 2 need not carve out two natural kinds of imagination. Aliens studying human imagination might not make it. Perhaps we do only because it involves what we feel is under our control and introspectively accessible, which is important for our ethical, pedagogical, and epistemological pursuits.

\section{Epistemological applications}

Several epistemological features follow directly from a dual process epistemology of imagination, independently of which imagination 0 we choose as our favourite. Imagination ${ }_{1}$, like all processes of its type, can generate knowledge when it is well-trained and applied in relevant contexts. Imagination, 2 , like all processes of its type, can generate knowledge when it follows inference rules (whether formal, experience-based, theoretical, etc.) on a system whose constraints are accurately modelled by those inference rules. Determining those inference rules is

\footnotetext{
${ }^{10}$ A different kind of criticism against using a dual process framework for epistemology of imagination is that system 1 processes are not "cognitive," in the sense that they do not count as thinking, reasoning, or intelligent behaviour of any kind (see, e.g., Di Nucci 2013; Dreyfus 2002; Stanley 2011). They therefore cannot form part of an epistemological account. See Fridland (2017) for arguments against this claim.
} 
the central question of recent work on the "logic of imagination" (see e.g., Wansing 2017; Berto 2018a, b), and also an important project for those working on the epistemology of thought experiments (see Sect. 4.3). What is novel is to see that the contributions to epistemic progress of imagination $_{1}$ and imagination ${ }_{2}$ are very different, and sometimes progress only comes through the combination of both. But more on that below.

First, it is important to see that imagination ${ }_{1}$ and 2 have different epistemological strengths and weaknesses. This is clear in cases where one is more reliable than the other. Imagination ${ }_{1}$ can be more reliable when previous experience directs it automatically to produce the correct output, while the conscious application of imagination 2 would confuse or mislead us. For example, an experienced stock broker might correctly imagine ${ }_{1}$ a crash in the market without being able to imagine $_{2}$ all the steps that would lead to it. Cases of the opposite kind appear whenever we find ourselves in sufficiently unpredictable territory (e.g., when we are first introduced to quantum mechanics) where imagination 1 will produce false predictions by extrapolating from previous experience, while imagination 2 can produce more reliable output through more careful means. For example, someone might easily imagine1 getting rich when faced with an investment opportunity, but, if they are not experienced with investments they should carefully imagine, in as much detail as possible, the likelihoods of what would actually happen. (For more examples of such conflicts, see Kahneman 2011).

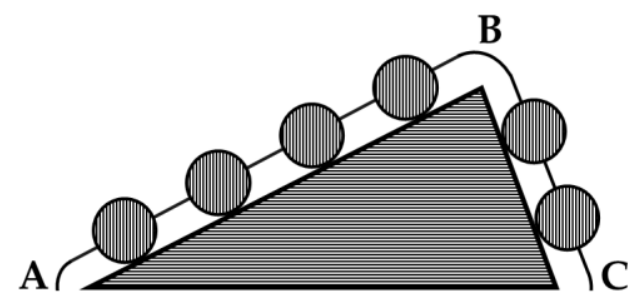

Fig. 1 A chain draped over a frictionless prism

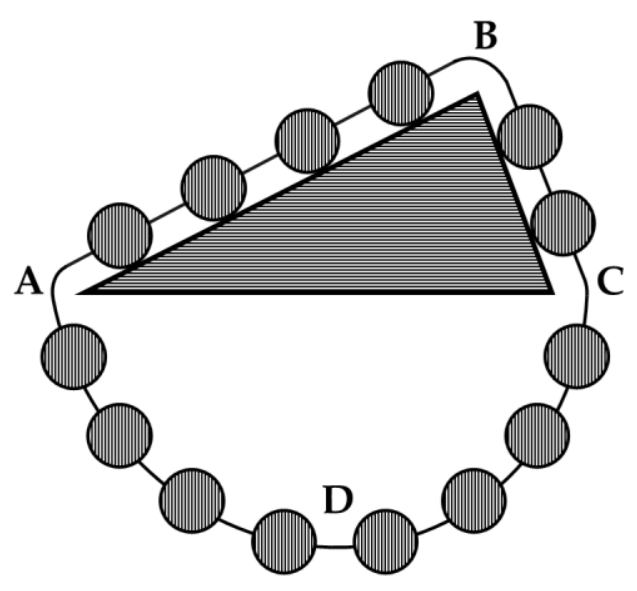

Fig. 2 The chain made into a loop 
Many of the most impressive epistemic uses of imagination will combine the strengths of each kind of imagination. Take Stevin's prism (Fig. 1), a frictionless system composed of a triangular prism with a chain of uniformly distributed mass draped over it (see Stevin 1586, 183-187; Mach 1883, 24-31).

How will the chain behave? We can put the question to ourselves and see if imagination ${ }_{1}$ delivers a response. Perhaps we find ourselves "seeing" the chain slide towards $A$, or towards $C$. ${ }^{11}$ At this point, Stevin asks us to alter the situation (using imagination 2 ) so that the chain is connected around the bottom of the prism, as in Fig. 2.

Again, we may ask ourselves what we should expect to happen, and see if an immediate answer comes via imagination 1 . If we don't get a response, we can also use imagination 2 : if the chain slides towards $A$, it will slide that way forever, and we will have a perpetual motion machine. The same for $C$. The slightest motion in either direction will cause a perpetual motion machine. Imagination $_{1}$ might remind us at this stage that perpetual motion machines are impossible (because if we try to imagine one, previous experience and background knowledge will flag this imagining as somehow "not right"-Mach calls this step "purely instinctive cognition" 1883 , 26). So the chain must be still. Newtonian mechanics tells us that the semicircular link of chain exerts equal downward force on $A$ and $C$, so removing it (using imagination 2 ) will not impact the balance of forces in the system. We have the same balance of forces in Fig. 1, so the behaviour of the system in Fig. 1 with respect to the forces acting on the chain must be the same as that in Fig. 2; since the chain in Fig. 2 is still, the chain in Fig. 1 will also be still. This is the solution to the initial question, and a wonderful result. But we can go further and use imagination 2 to alter the shape of the prism to any shape we like, and we will get the same result. The chain will not slide. This result therefore applies to any chains (with uniform mass distributions) draped over frictionless prisms of any shape, as long as the system is perpendicular to gravity and the chain reaches both of its ends around the shape to the horizontal. This result is due to the fruitful combination of imagination $_{1}$ and ${ }_{2}$ : imagination im sets things up, imagination $_{1}$ evolves the system. Imagination $_{2}$ introduces a change, imagination $_{1}$ tries to evolve the system, and finds itself stumped. This we interpreted in a way that inspired imagination ${ }_{2}$ to explore the scenario further until we were satisfied.

The dual process model improves explanations of imagination-based epistemic progress by focusing on the different contributions of the two kinds of imagination, each of which is reliable for different reasons. I see no impediment to using this framework wherever epistemicallyrelevant imagination appears, whether in model-based reasoning, modal reasoning, thought experiments, hypothesis creation and exploration, experimental design, or data interpretation, though in-depth case studies are required to make this convincing. Instead of attempting this, I will quickly sketch how the account deals with two important unresolved issues in epistemology of imagination, as well as how it intersects with the literature on thought experiments.

\subsection{Skepticism about epistemic uses of imagination}

\footnotetext{
${ }^{11}$ Or "intuiting," to allow for the possibility of non-perceptual imagination . $_{1}$
} 
There are several reasons one might be skeptical about the epistemic reliability of imagination. Two are helpfully identified in the history of science by McAllister (2013a). On the one hand, imagination does not appear to be constrained. This makes it misleading as a guide to reality (Thagard 2010, 2014): we can imagine whatever we want, including false or perhaps impossible things. On the other hand, imagination does appear constrained, and rather severely: we imagine only what occurs to us, or what we've been primed to imagine. As J. B. S. Haldane puts it, "My own suspicion is that the universe is not only queerer than we suppose, but queerer that we can suppose" (quoted in McAllister 2013a, p. 15).

These worries correspond to two arguments that have been used by scientists to contest the value of imagination in science, which are labeled by McAllister as the problems of "poverty" and "arbitrariness" (McAllister 2013a, p. 12). The poverty of imagination refers to our tendency to imagine in ways that are tightly constrained by our previous experience of the world, as when people who are told to imagine an alien typically imagine something with two arms, two legs, a head and two eyes. The arbitrariness of imagination refers to our ability to imagine anything we want: it is underconstrained by the world, and therefore not a reliable informant about the world.

Together, this forms a historical puzzle: how can "the" imagination be dangerously over and underconstrained for epistemological use in science? To be clear, this puzzle is about how to rationally reconstruct the conflicting expressions of doubt made by scientists toward epistemic uses of imagination. To resolve it, we begin by asking whether there is any kind of imagination that suffers from both poverty and arbitrariness. Imagination 0 can be exercised in under and overconstrained ways, but never both at the same time: it would be impossible to perform an action that was at once the result of a decision based on completely free choice between many equally good options (arbitrary) and also the result of a decision that selected only the first, most obvious option, without considering any other options (impoverished). There is no paradox here.

Still, the reasons for skepticism remain, and a dual epistemology is useful for understanding and addressing them. Some exercises of imagination ${ }_{0}$ will be underconstrained and others will be overconstrained (though never both at once). Fortuitously, these two causes for concern line up with the two kinds of imagination. Imagination 2 is under our conscious control, and it is not constrained by logic, perception, the laws of nature, or our background knowledge. It is therefore underconstrained in the sense relevant for skepticism. Imagination ${ }_{1}$ produces outputs automatically: we have little or no choice in what imagination ${ }_{1}$ delivers. It is therefore overconstrained in the sense relevant for skepticism. Do these considerations show that imagination $_{1}$ and 2 should be deemed epistemically unreliable?

Imagination ${ }_{2}$ is underconstrained because its processes are under our control, which means we can direct it in ways that violate epistemic constraints like representational accuracy. Yet, consider computer simulations, which can be programmed in an infinite number of ways, many of which would yield false results for a given system's evolution. This possibility should not, on its own, lead us to conclude that computer simulations are epistemically unreliable in principle. Equally, the mere possibility that imaginative 2 processes can proceed in any direction we wish is not (in principle) an epistemological fault, because we can also choose to imagine 2 in epistemically reliable ways. Thus the arbitrariness objection does not succeed in casting doubt on 


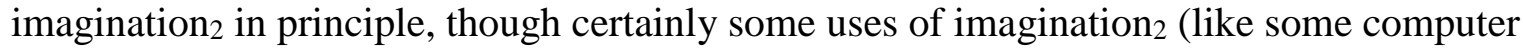
simulations) can fail for being relevantly underconstrained.

While imagination $_{2}$ is the proper target of the arbitrariness objection, imagination is $_{1}$ the proper target of the other. Imagination ${ }_{1}$ appears overconstrained because its processes are not under our direct control: they are constrained by previous experience and background knowledge. But even at its most automatic and least conscious, it is still under our control in the higher-order sense that we can choose how to train it, and when we should trust it. After many years spent deriving results in a theoretical framework or experimenting with a system of interest, scientists improve their automatic imaginings about possible behaviours of a system, or the directions in which to pursue inquiry. A firefighter automatically imagines a backdraft before opening a door, and rightly decides not to open it. It is not, therefore, our lack of control over imagination 1 that is epistemologically worrying, but our lack of training and experience. And that is, to some extent, under our control. Thus while imagination ${ }_{1}$ is the proper object of the poverty criticism, this

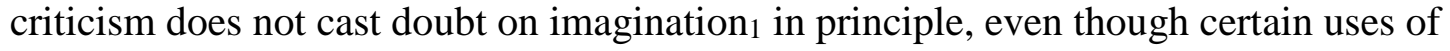
imagination $_{1}$ can be impoverished in worrying ways.

In sum, imagination 0 can be impoverished and arbitrary, though not at the same time. Imagination $_{2}$ will typically be the proper target of the arbitrariness objection, though we can choose to operate it in accurate ways if we wish. Imagination 1 will typically be the proper target of the poverty objection, though it can be trained through relevant experience to produce reliable outputs in a given context.

\subsection{Optimism about epistemic uses of imagination}

Even if "the imagination sometimes tends toward unreflective conservativism and at other times tends toward flights of fancy, certain lines of counterfactual thought that are carefully constructed and doggedly followed can lead to extraordinary innovation" (Meynell 2018, p. 508). Optimism about the power of imagination leads to what Amy Kind and Peter Kung call the "puzzle of imaginative use" $(2016,1)$ :

Imagination is put to two distinct and seemingly incompatible uses. Imagination is sometimes used to enable us to escape or look beyond the world... Yet imagination is also sometimes used to enable us to learn about the world as it is, as when we plan or make decisions or make predictions about the future... But how can a single mental activity successfully be put to both uses?

The puzzle is that imagination is not restricted by how the world is, yet it can sometimes teach us how the world is. The puzzle can be addressed in the following way. Imagination 0 is the ability that allows us to "escape or look beyond the world" and also learn about the world, and it operates through exercises of imagination ${ }_{1}$ and ${ }_{2}$. While an entire imaginative episode (e.g., a thought experiment) might teach us about aspects of reality while also scorning aspects of reality, no individual act of imagination within that episode will at the very same instant both scorn and inform us about the very same aspect of reality. So there is no paradox here. Still, we are left with the interesting epistemological question of how to combine scorn and respect for reality. The key is to see that imagination by its nature always scorns at least one aspect of 
reality, by introducing or deleting aspects, but it can always be constrained in epistemologically relevant ways. Training and experience automatically constrain imagination ${ }_{1}$, while choosing to obey the relevant rules of reasoning and choosing to manipulate accurate representations constrains imagination 2 . And it is through these constraints that information about the world makes its way from our previous knowledge and experience to the conclusion of the imaginative episode: some aspects of reality are scorned and others are not, and it is the ones that are not which carry justificatory power. ${ }^{12,13}$

\subsection{The epistemology of thought experiments}

There is a large and growing literature on thought experiments in science, with a number of positions that aim to answer what is called "the epistemological problem of thought experiments in the sciences" (Norton 2004a, p. 1139). The problem concerns the "puzzling fact that thought experiments often have novel empirical import even though they are conducted entirely inside one's head" (Horowitz and Massey 1991, p. 1). ${ }^{14}$

Positions on this problem range across all the major epistemological "-isms," including empiricism (Norton 1991, 1996, 2004a, 2004b) rationalism (Brown 1986, 1991, 2004), naturalism (Gendler 2004; Miščević 1992, 2007; Nersessian 1992, 1993, 2007, 2008, 2018), phenomenology (Hopp 2014, Wiltsche 2018), Kantianism (Buzzoni 2013, 2018), pluralism (Bokulich and Frappier 2018), contextualism (McAllister 2018), and skepticism (Meinong 1907, pp. 276-277; Thagard 2010, p. 209).

The modern form of the discussion is due to the disagreement between James R. Brown and John D. Norton, a Platonist and an empiricist. Brown writes, "Thought experiments (at least in some cases) allow us to intuit laws of nature. Intuitions, remember, are nonsensory perceptions of abstract entities. Because they do not involve the senses, they transcend experience, and give us a priori knowledge of the laws of nature" (Brown 2004, p. 34). Norton replies: "If this can be taken at face value, thought experiments perform epistemic magic" (Norton 2004b, p. 44). Norton's account claims that thought experiments are nothing other than arguments that manipulate propositions which are ultimately justified by experience. This disagreement between Brown and Norton is the starting point for the rest of the literature. Nancy Nersessian, for example, argues that the mental model view (which portrays thought experiments as manipulations of mental

\footnotetext{
${ }^{12}$ This is in line with Kind and Kung's own solution to the puzzle, which is that "imagination's ability to serve an instructive function depends on the presence of constraints" (2016, p. 13). Their solution relies on two kinds of constraint: architectural and those implied by free will. By recharacterizing architectural constraints as constraints on imagination $_{1}$ and those implied by free will as constraints on imagination ${ }_{2}$, we can speak the language of cognitive science and take advantage of the rest of the dual process model of cognition, while avoiding metaphysical difficulties concerning "architectures of imagination" and free will.

${ }^{13}$ I do not want to commit myself to the position that imagination is only epistemically efficacious when it is constrained by the world, or that imagination always produces knowledge through truth preservation. This is merely one way to explain the ability of imagination to produce knowledge. Sometimes, imagination works best when it breaks radically from what seemed like reasonable constraints.

${ }^{14}$ Thomas Kuhn's version of this puzzle is: "How, then, relying exclusively upon familiar data, can a thought experiment lead to new knowledge or to a new understanding of nature?" (1964, p. 241). A more recent wording of the problem is Norton's: "Thought experiments are supposed to give us knowledge of the natural world. From where does this knowledge come?" (2004b, p. 44). It is fair to ask whether the different statements of this question are really equivalent (see Stuart et al. 2018b, pp. 10-11 for other options).
} 
models) eliminates the need for "a priori knowledge of nature" but also the need to portray everything as regimented logical reasoning (2007, p. 126). There are very few if any in the current debate who take empiricism and rationalism to be the only two viable options.

Now that most of the possible "-isms" are represented and each has produced an epistemology of thought experiments that corresponds with the assumptions of its "-ism," the literature is in danger of stagnation. This is evidenced by the large number of characterizations of thought experiments that have piled up. Thought experiments are arguments (Norton 1991, 1996, 2004a, 2004b), windows into Plato's heaven (Brown 1986, 1991, 2004), intuition pumps (Dennett 1984, 2013), experiments (Gooding 1992a, 1992b; Sorensen 1992; Stuart 2016b), manipulations of mental models (Gendler 2004; Miščević 1992, 2007; Nersessian 1992, 1993, 2007, 2008, 2018), examples (Elgin 2014; Ierodiakonou 2018), "props" for the imagination (Meynell 2014, 2018; Salis and Frigg forthcoming), invitations to imagine (Becker 2018), fictions (Elgin 2014), tests of a theory's potential (Bokulich 2001; Lennox 1991), rhetorical devices (Lennox 1991), and many other things.

It is important to discuss the role of imagination in thought experiments (Arcangeli 2010), at least partially because it goes some way toward revealing the assumptions underlying the different accounts. I will not go through each of these accounts in detail, but show how, using the dual process model, we can get many of them to speak the same language, clarifying the debate and reducing the possibility of talking past one another.

Norton argues that thought experiments are best understood epistemologically as arguments. He also makes the descriptive psychological claim that thought experiments actually are arguments whenever they are performed (1996, p. 354; 2004b, p. 51). When we perform a thought experiment, we are doing nothing other than producing or following through an argument, whatever else we may think or feel we are doing. Therefore if Norton is right, imagination in $_{1}$ plays no role in thought experiments at all —not just epistemologically, but psychologically as wellsince arguments are conscious manipulations of propositions, and imagination ${ }_{1}$ is unconscious. We never argue (in the logician's sense of argument) without being aware that we're doing it. So thought experiments for Norton are completely located in the realm of imagination.

Daniel Dennett's characterization of thought experiments is the opposite. He claims that thought experiments are intuition pumps. Here, the core of a thought experiment is the automatic, unconscious, intuitive response that it produces. For Dennett, thought experiments "are not supposed to clothe strict arguments that prove conclusions from premises. Rather, their point is to entrain a family of imaginative reflections in the reader that ultimately yields not a formal conclusion but a dictate of "intuition"' (Dennett 1984, p. 12). Dennett therefore understands thought experiments as powerful producers of imaginative1 responses.

I interpret Brown as claiming that thought experiments use both kinds of imagination: imagination $_{2}$ is responsible for the set-up of a thought experiment, and imagination the rational $_{1}$ insight. This would accord with his metaphor of rational "seeing": perception (a cognitive process) proceeds automatically, unconsciously and mostly without our control, so too does rational insight, which has all of the phenomenological hallmarks of imagination ${ }_{1}$. 
Nersessian, Miščević, Gendler, and others who portray thought experiments as mental models, will go along with Brown in emphasizing epistemological roles for both imagination and $_{2}$, but they will try to de-motivate Brown's Platonism by naturalizing imagination ${ }_{1}$. According to them, imagination $_{1}$ is the result of evolution, tacit knowledge, expectation, and training. No rational insight required.

Another view of thought experiments sees them as non-metaphorical members of the experiment family, that is, as a species of genuine experiments (Gooding 1992a, b; Sorensen 1992; Stuart 2016b). This view is compatible with Brown's Platonism since Brown argues that experiments are a good way of opening rational access to laws of nature. It is also compatible with the mental model view, since experiments and model-based reasoning can both be understood as manipulations and (quasi-) observations of representations. In any case, on a dual process model of imagination where thought experiments are a proper set of the general class of experiments, all thought experiments must include some use of imagination 2 , since we cannot experiment without consciously intending to. Imagination ${ }_{2}$ sets up the thought experiment, keeps it on track

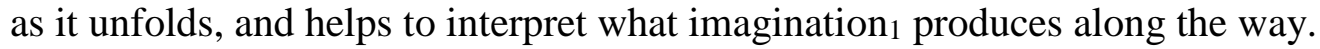

Whatever view we take on scientific thought experiments, the dual process model of imagination suggests the following framework for discussing them. Psychologically, thought experiments should be understood as cognitive processes. Whether both imagination ${ }_{1}$ and 2 are involved is an empirical matter. If it turns out that both are involved, we should expect that the performance of any given thought experiment will rely more or less on imagination ${ }_{1}$ or 2 , depending on the performer's abilities and experience. A child might need to use imagination 2 quite a lot when performing Galileo's thought experiment with falling bodies, while the same conclusion might come much more automatically (by imagination ${ }_{1}$ ) for a seasoned physicist.

Epistemologically, we can focus our efforts more or less on the input of imagination or $_{2}$ (with Norton or Dennett) or we can include the input of both (Brown, Nersessian, Miščević, and others). We should be consistent with empirical evidence, however, and not ignore the importance of a kind of imagination that is present, nor should we inflate the importance of a kind of imagination that is not present.

With these considerations we clarify one way that different positions in the debate have talked past one another: they posit different kinds of imagination as relevant for the description and epistemology of thought experiments. It also allows us to recast many of the different characterizations of thought experiments into the same language. In terms of imagination ${ }_{1}$ and 2 , Norton and Dennett form two extreme positions while others champion dual characterizations. And if it turns out that thought experiments need both kinds of imagination to succeed, this provides support for epistemological accounts consistent with this. In my opinion it seems likely that we will need to invoke both kinds of imagination. As Kendall Walton suggests, "a chain of imaginings begun deliberately almost always develops further on its own" (Walton 1990, p. 14). And the opposite is also true: spontaneous imaginings very often prompt more deliberate cognitive work. These psychological connections between imagination ${ }_{1}$ and $_{2}$, if they exist, are likely to be crucial for any epistemology of thought experiments or imagination that takes practice seriously. 
Finally, the dual process model of imagination opens new avenues for the epistemological evaluation of thought experiments. To demonstrate, I'll briefly discuss how it could productively complicate the mental models and experimentalist epistemologies of thought experiments.

Nersessian argues that mental model-use can produce knowledge when the models manipulate "representations that derive from real-world experiences... [in a way that conforms] to the constraints of that context and of the practices in which it is being conducted" (Nersessian 2018, p. 322). The dual process model of imagination duplicates the number of epistemologically relevant constraints such that imagination produces new knowledge when it (1) draws on accurate representations unconsciously supplied by imagination ${ }_{1},(2)$ operates by rules faithful to aspects of the target system unconsciously followed by imagination ${ }_{1},(3)$ uses accurate representations created consciously by imagination, ${ }_{2}$ and (4) operates using rules faithful to aspects of the target system consciously created and/or followed by imagination 2 . On this view, the same thought experiment can now be evaluated epistemologically in twice as many ways.

On the experimentalist view, we start by recognizing that the performance of an experiment and its theoretical application can and perhaps should be evaluated independently (Radder 1996). That is, epistemologically speaking, some experimental manipulations are better than others, and some interpretations of the outcomes of those manipulations are better than others. For example, there were many performances of the Michelson-Morley experiment, some carried out underground, some on hilltops, and some in hot air balloons (Swenson 1970), and some of these were more accurate than others. Likewise, there were many interpretations of what this experiment meant for ether theory and Special Relativity. This insight transfers easily to thought experiments (De Mey 2003; Häggqvist 1996). Schrödinger's cat, for example, is a good thought experiment in performance: it provides understanding concerning the empirical consequences of the Copenhagen interpretation, so we still use it to introduce students to entanglement and the measurement problem in quantum mechanics. But it is not a good thought experiment when interpreted (as Schrödinger intended) as an argument against the viability of the Copenhagen interpretation.

Combining the dual process model of imagination with the experimentalist view, we say that just like a real experiment, we must pay attention to the epistemological features that give us confidence in the performance and interpretation of a thought experiment. But now, the performance of the thought experiment must be divided into the set up (imagination 2 ) and the "natural" outcome of the set up (imagination 1 ). That is, we must ensure that imagination 2 sets things up such that we receive a relevant and reliable output from imagination 1 . In terms of the interpretation, again both kinds of imagination will be relevant. Imagination 2 is what we will typically use to evaluate the outcome, for example, whether we should take some imagined1 scenario as evidence that that scenario is possible. But we cannot exhaustively explain the epistemological quality of the interpretation by reference to imagination 2 , since some aspects of the interpretation will be made intuitively using imagination ${ }_{1}$. For example, logic and background knowledge do not tell us whether a superposed cat is possible in our world. For this aspect of the interpretation, we rely on previous experience channelled through imagination . $_{\text {. }}$ Again, by incorporating a dual process model of imagination, experimentalist epistemologies of thought experiments double their available resources for evaluating thought experiments. 


\section{Conclusion}

I have argued that if we want to do epistemology of imagination, we should employ a processbased epistemology as opposed to a state-based or trait-based epistemology. Further, any general framework for epistemology of imagination must be abstract enough to cohere with insights from both philosophy and cognitive science, and specific enough to explain epistemically productive uses of imagination. This paper presented a framework consisting of the definition schema presented in Sect. 2 combined with the dual process model of cognition. I have argued that a dual process epistemology of imagination provides useful ways of evaluating the different imaginative activities that form part of epistemological uses of imagination. And I have argued that such an account also performs well concerning historical and epistemological puzzles about the epistemic use of imagination in science, as well as the debate about scientific thought experiments.

Acknowledgements: I'd like to thank Marco Buzzoni, Nancy Nersessian, Catherine Elgin, John Norton, Margherita Arcangeli, Jim Brown, Michael Hannon, Philip Thonemann, Bryan Roberts, Michael Strevens, Deena Weisberg, Alison Hills, Christoph Baumberger, Susan Carey, Boris Babic, Victoria Hoog, Agnes Bolinska, Maël Pégny, Leonardo Bich, Carol Cleland, Andrew Inkpen, Mattias Unterhuber and audiences at the Summer Seminar on Understanding at Fordham University, the London School of Economics Research Seminar in the Philosophy of Natural Sciences, the Nordic Network for Philosophy of Science, the philosophy of science annual conference in Dubrovnik and the Imagination and Knowledge conference in Konstanz. This paper was funded by the University of Pittsburgh's Center for Philosophy of Science, as well as SSHRC Grant Number 756-2016-0830.

\section{References}

Aggleton, J. P., Vann, S. D., Denby, C., Dix, S., Mayes, A. R., Roberts, N., et al. (2005). Sparing of the familiarity component of recognition memory in a patient with hippocampal pathology. Neuropsychologia, 43, 1810-1823.

Arcangeli, M. (2010). Imagination in thought experimentation: Sketching a cognitive approach to thought experiments. In L. Magnani, et al. (Eds.), Model-based reasoning in science and technology (pp. 571-587). Berlin: Springer.

Arcangeli, M. (2017). Interacting with emotions: Imagination and supposition. The Philosophical Quarterly, 67, 730-750. https://doi.org/10.1093/pq/pqx007.

Atkinson, R. C., \& Juola, J. F. (1973). Factors influencing the speed and accuracy of word recognition. In S. Kornblum (Ed.), Attention and performance IV (pp. 583-612). New York: Academic Press.

Atkinson, R. C., \& Juola, J. F. (1974). Search and decision processes in recognition memory. In D. H. Krantz, R. C. Atkinson, \& P. Suppes (Eds.), Contemporary developments in mathematical psychology (pp. 243-290). San Francisco: Freeman.

Becker, A. (2018). Thought experiments in Plato. In M. T. Stuart, et al. (Eds.), The Routledge companion to thought experiments (pp. 44-56). London: Routledge.

Berto, F. (2018a). Taming the runabout imagination ticket. Synthese. https://doi.org/10.1007/s1122 9-018-1751-6. 
Berto, F. (2018b). Aboutness in imagination. Philosophical Studies, 175, 1871-1886. Bokulich, A. (2001). Rethinking thought experiments. Perspectives on Science, 9, 285-307.

Bokulich, A., \& Frappier, M. (2018). On the identity of thought experiments: Thought experiments rethought. In M. Stuart, et al. (Eds.), The Routledge companion to thought experiments (pp. 545- 557). London: Routledge.

Botzung, A., Denkova, E., \& Manning, L. (2008). Experiencing past and future personal events: Functional neuroimaging evidence on the neural bases of mental time travel. Brain and Cognition, 66, 202-212.

Brown, J. R. (1986). Thought experiments since the scientific revolution. International Studies in the Philosophy of Science, 1, 1-15.

Brown, J. R. (1991/2011). The laboratory of the mind: Thought experiments in the natural sciences. London: Routledge.

Brown, J. R. (2004). Why thought experiments do transcend empiricism. In C. Hitchcock (Ed.), Contemporary debates in the philosophy of science (pp. 23-43). Malden: Blackwell.

Buzzoni, M. (2008). Thought experiment in the natural sciences. Würzburg: Königshausen \& Neumann. Buzzoni, M. (2013). Thought experiments from a Kantian point of view. In M. Frappier, et al. (Eds.), Thought experiments in science, philosophy, and the arts. London: Routledge.

Buzzoni, M. (2018). Kantian accounts of thought experiments. In M. Stuart, et al. (Eds.), The Routledge companion to thought experiments (pp. 327-341). London: Routledge.

Byrne, R. M. J. (2005). The rational imagination: How people create alternatives to reality. Cambridge: MIT Press.

Cipolotti, L., Bird, C., Good, T., Macmanus, D., Rudge, P., \& Shallice, T. (2006). Recollection and familiarity in dense hippocampal amnesia: A case study. Neuropsychologia, 44, 489506.

Clement, J. (2008). Creative model construction in scientists and students: The role of imagery, analogy, and mental simulation. New York: Springer.

Clement, J. (2009). Analogy reasoning via imagery: The role of transformations and simulations. In B. Kokinov, K. Holyoak, \& D. Gentner (Eds.), New frontiers in analogy research. Sofia: New Bulgarian University Press.

Currie, G., \& Ravenscroft, I. (2002). Recreative minds. Oxford: OUP.

De Mey, T. (2003). The dual nature view of thought experiments. Philosophica, 72, 61-78. Dennett, D. (1984). Elbow room: The varieties of free will worth wanting. Cambridge: MIT Press.

Dennett, D. (2013). Intuition pumps: And other tools for thinking. New York: W. W. Norton and Company.

Di Nucci, E. (2013). Mindlessness. Cambridge: Cambridge Scholars Publishing.

Dreyfus, H. (2002). Intelligence without representation: Merleau Ponty's critique of representation. Phenomenology and the Cognitive Sciences, 1, 367-383.

Elgin, C. Z. (2014). Fiction as thought experiment. Perspectives on Science, 22, 221-241.

Engel, P. (2016). The epistemology of stupidity. In M. Á. F. Vargas (Ed.), Performance epistemology: Foundations and applications. Oxford: Oxford University Press.

Evans, J. (2008). Dual-processing accounts of reasoning, judgment, and social cognition. Annual Review of Psychology, 59, 255-278.

Evans, J., \& Frankish, K. (2009). In two minds: Dual processes and beyond. Oxford: Oxford University Press. 
Evans, J., \& Over, D. (1996). Rationality and reasoning. Hove: Psychology Press.

Fortin, N. J., Wright, S. P., \& Eichenbaum, H. (2004). Recollection-like memory retrieval in rats is dependent on the hippocampus. Nature, 431, 188-191.

Frankish, K. (2004). Mind and supermind. Cambridge: Cambridge University Press.

Frappier, M., Meynell, L., \& Brown, J. R. (Eds.). (2013). Thought experiments in science, philosophy, and the arts. London: Routledge.

Fridland, E. (2017). Automatically minded. Synthese, 194, 4337-4363.

Funkhouser, E., \& Spaulding, S. (2009). Imagination and other scripts. Philosophical Studies, 143(3), 291-314.

Gendler, T. S. (2000). Thought experiment: On the powers and limits of imaginary cases. London: Routledge.

Gendler, T. S. (2004). Thought experiments rethought - and reperceived. Philosophy of Science, $71,1152-1163$.

Gendler, T. S. (2007). Philosophical thought experiments, intuitions and cognitive equilibrium. Midwest Studies in Philosophy, 31, 68-89.

Gilbert, D. (1999). What the mind's not. In S. Chaiken \& Y. Trope (Eds.), Dual-process theories in social psychology (pp. 3-11). New York: Guilford Press.

Goldman, A. (2006). Imagination and simulation in audience responses to fiction. In S. Nichols (Ed.), The architecture of the imagination (pp. 41-56). Oxford: Oxford University Press.

Gooding, D. (1992a). The procedural turn; or, why do thought experiments work? In R. N. Giere (Ed.),

Cognitive models of science (pp. 45-76). Minneapolis: University of Minnesota Press.

Gooding, D. (1992b). What is experimental about thought experiments? PSA: Proceedings of the Biennial Meeting of the Philosophy of Science Association, 2, 280-290.

Hadamard, J. (1996). The mathematician's mind: The psychology of invention in the mathematical field. Princeton: Princeton University Press.

Häggqvist, S. (1996). Thought experiments in philosophy. Stockholm: Almqvist and Wiksell International.

Hintzman, D. L., \& Curran, T. (1994). Retrieval dynamics of recognition and frequency judgments: Evidence for separate processes of familiarity and recall. Journal of Memory and Language, 33, 1-18.

Holton, G. (1998/1978). The scientific imagination. Harvard: Harvard University Press. Hopp, W. (2014). Experiments in thought. Perspectives on Science, 22, 242-263.

Horowitz, T., \& Massey, G. (1991). Thought experiments in science and philosophy. Lanham: Rowman and Littlefield.

Ierodiakonou, K. (2018). The triple life of ancient thought experiments. In M. Stuart, et al. (Eds.), The Routledge companion to thought experiments (pp. 31-43). London: Routledge.

Jacoby, L. L. (1991). A process dissociation framework: Separating automatic from intentional uses of memory. Journal of Memory and Language, 30, 513-541.

Jacoby, L. L., \& Dallas, M. (1981). On the relationship between autobiographical memory and perceptual learning. Journal of Experimental Psychology: General, 3, 306-340.

Kahneman, D. (2011). Thinking fast and slow. New York: Farrar, Straus and Giroux.

Kahneman, D., \& Miller, D. T. (1986). Norm theory: Comparing reality to its alternatives. Psychological Review, 93, 136-153. 
Kahneman, D., Slovic, P., \& Tversky, A. (1982). Judgment under uncertainty: Heuristics and biases. Cambridge: Cambridge University Press.

Khemlani, S. S., Mackiewicz, R., Bucciarelli, M., \& Johnson-Laird, P. (2013). Kinematic mental simulations in abduction and deduction. Proceedings of the National Academy of Science of the United States of America, 110, 16766-16771.

Kieran, M., \& McIver Lopes, D. (2003a). Introduction. In M. Kieran \& D. McIver Lopes (Eds.), Imagination, philosophy, and the arts. London: Routledge.

Kieran, M., \& McIver Lopes, D. (Eds.). (2003b). Imagination, philosophy, and the arts. Routledge: London.

Kind, A. (Ed.). (2016). The Routledge handbook of philosophy of imagination. London: Routledge. Kind, A., \& Kung, P. (Eds.). (2016). Knowledge through imagination. Oxford: OUP.

Kosslyn, S. (1994). Image and brain: The resolution of the imagery debate. Cambridge: MIT Press.

Kosslyn, S., Behrmann, M., \& Jeannerod, M. (1995). The cognitive neuroscience of mental imagery. Neuropsychologia, 33, 1335-1344.

Kosslyn, S., Thompson, W. L., \& Ganis, G. (2006). The case for mental imagery. Oxford: Oxford University Press.

Kuhn, T. S. (1964). A function for thought experiments. In T. Kuhn (Ed.), The essential tension (pp. 240-265). Chicago: University of Chicago Press.

Lennox, J. G. (1991). Darwinian thought experiments: A function for just-so stories. In T. Horowitz \& G. Massey (Eds.), Thought experiments in science and philosophy. Lanham: Rowman and Littlefield.

Mach, E. (1883/1919). The science of mechanics: A critical and historical account of its development (J. McCormack, Trans.). Chicago: Open Court.

Mandel, D., Hilton, D., \& Catellani, P. (2005). The psychology of counterfactual thinking. New York: Routledge.

Mandler, G. (1980). Recognizing: The judgment of previous occurrence. Psychological Review, 87, 252-271.

Markman, K., Klein, W., \& Suhr, J. (2009). Handbook of imagination and mental simulation. New York: Taylor and Francis.

McAllister, J. (2013a). Thought experiment and the exercise of imagination in science. In M. Frappier, et al. (Eds.), Thought experiments in philosophy, science, and the arts. New York: Routledge.

McAllister, J. (2013b). Reasoning with visual metaphors. The Knowledge Engineering Review, $28,367-379$.

McAllister, J. (2018). Historicism and cross-culture comparison. In M. Stuart, et al. (Eds.), The Routledge companion to thought experiments (pp. 425-438). London: Routledge.

McGinn, C. (2004). Mindsight: Image, dream, meaning. Cambridge: Harvard University Press.

Meinong, A. (1907/1973). Das Gedankenexperiment. In R. Haller and R. Kindinger (Eds.), Über die Stellung der Gegenstandstheorie im System der Wissenschaften. Graz-Austria: Akademische Druck und Verlagsanstalt.

Meynell, L. (2014). Imagination and insight: A new account of the content of thought experiments. Synthese, 191, 4149-4168.

Meynell, L. (2018). Images and imagination in thought experiments. In M. Stuart, et al. (Eds.), The Routledge companion to thought experiments (pp. 498-511). London: Routledge. 
Miščević, N. (1992). Mental models and thought experiments. International Studies in the Philosophy of Science, 6, 215-226.

Miščević, N. (2007). Modelling intuitions and thought experiments. Croatian Journal of Philosophy, 7, 181-214.

Moran, R. (2017). The philosophical imagination: Selected essays. Oxford: Oxford University Press. Nanay, B. (2015). Perceptual content and the content of mental imagery. Philosophical Studies, 172, 1723-1736.

Nersessian, N. J. (1992). How do scientists think? Capturing the dynamics of conceptual change in science. In R. N. Giere (Ed.), Cognitive models of science. Minneapolis: University of Minnesota Press.

Nersessian, N. J. (1993). In the theoretician's laboratory: Thought experimenting as mental modeling.

Proceedings of the Philosophy of Science Association, 2, 291-301.

Nersessian, N. J. (2007). Thought experiments as mental modelling: Empiricism without logic. Croatian Journal of Philosophy, 7, 125-161.

Nersessian, N. J. (2008). Creating scientific concepts. Cambridge: MIT Press.

Nersessian, N. J. (2018). Cognitive science, mental modeling, and thought experiments. In M. Stuart, et al. (Eds.), The Routledge companion to thought experiments (pp. 309-326). London: Routledge.

Nichols, S. (2006). Architecture of the imagination. Oxford: Clarendon Press.

Nichols, S., \& Stich, S. (2000). A cognitive theory of pretense. Cognition, 74, 115-147. Nichols, S., \& Stich, S. (2003). Mindreading. New York: Oxford University Press.

Norton, J. D. (1991). Thought experiments in Einstein's work. In T. Horowitz \& G. Massey (Eds.), Thought experiments in science and philosophy. Lanham: Rowman and Littlefield.

Norton, J. D. (1996). Are thought experiments just what you thought? Canadian Journal of Philosophy, 26, 333-366.

Norton, J. D. (2004a). On thought experiments: Is there more to the argument? Philosophy of Science, 71, 1139-1151.

Norton, J. D. (2004b). Why thought experiments do not transcend empiricism. In C. Hitchcock (Ed.), Contemporary debates in the philosophy of science. Malden: Blackwell.

Pearson, J., Naselaris, T., Holmes, E. A., \& Kosslyn, S. M. (2015). Mental imagery: Functional mechanisms and clinical applications. Trends in Cognitive Sciences, 19, 590-602.

Pylyshyn, Z. W. (2002). Mental imagery: In search of a theory. Behavioral and Brain Sciences, $25,157-182$.

Radder, H. (1996). In and about the world: Philosophical studies of science and technology. Albany: State University of New York Press.

Richardson, A. (1969). Mental imagery. New York: Springer Publishing Company Inc.

Salis, F., \& Frigg, R. (forthcoming). Capturing the scientific imagination. In P. Godfrey-Smith, \& A. Levy (Eds.), The scientific imagination. New York: Oxford University Press.

Sloman, S. A. (1996). The empirical case for two systems of reasoning. Psychological Bulletin, $119,3-22$.

Sloman, S. A. (2002). Two systems of reasoning. In T. Gilovich, D. Griffin, \& D. Kahneman (Eds.), Heuristics and biases: The psychology of intuitive judgment (pp. 379-398). Cambridge: Cambridge University Press. 
Sorensen, R. (1992). Thought experiments. Oxford: Oxford University Press. Stanley, J. (2011). Know how. Oxford: Oxford University Press.

Stanovich, K. E. (1999). Who is rational? Studies of individual differences in reasoning. Mahwah, NJ: Elrbaum.

Stevenson, L. (2003). Twelve conceptions of imagination. British Journal of Aesthetics, 43, 238259.

Stevin, S. (1586/1955). The principal works of Simon Stevin. In E. Crone, E. J. Dijksterhuis, R. J. Forbes, M. G. J. Minnaert \& A. Pannekoek (Eds.). Amsterdam: C. V. Swets \& Zeitlinger.

Strawson, P. F. (1970). Imagination and perception. In L. Foster \& J. W. Swanson (Eds.), Experience and theory (pp. 31-54). Amherst, MA: University of Massachusetts Press.

Strohminger, M. (2016). Review of Amy Kind and Peter Kung (Eds.), Knowledge through imagination. Resource Document. Notre Dame Philosophical Review. http://ndpr.nd.edu/news/knowledge-through-imagination/. Accessed January 2018.

Stuart, M. T. (2016a). Taming theory with thought experiments: Understanding and scientific progress. Studies in the History and Philosophy of Science Part A, 58, 24-33.

Stuart, M. T. (2016b). Norton and the logic of thought experiments. Axiomathes, 26, 451-466.

Stuart, M. T. (2017). Imagination: A sine qua non of science. Croatian Journal of Philosophy, 49, 9-32.

Stuart, M. T. (2018). How thought experiments increase understanding. In M. Stuart, et al. (Eds.), The Routledge companion to thought experiments (pp. 526-544). London: Routledge.

Stuart, M. T. (forthcoming). The role of imagination in social scientific discovery: Why machine discoverers will need imagination algorithms. In M. Addis et al. (Eds.), Scientific discovery in the social sciences. Springer Synthese Library.

Stuart, M., Fehige, Y., \& Brown, J. R. (Eds.). (2018a). The Routledge companion to thought experiments. London: Routledge.

Stuart, M., Fehige, Y., \& Brown, J. R. (2018b). Thought experiments: The state of the art. In M. T. Stuart, et al. (Eds.), The Routledge companion to thought experiments (pp. 1-28). London: Routledge.

Suddendorf, T., Addis, D. R., \& Corballis, M. C. (2009). Mental time travel and the shaping of the human mind. Philosophical Transactions of the Royal Society of London B: Biological Sciences, 364, 1317-1324.

Suddendorf, T., \& Busby, J. (2003). Mental time travel in animals? Trends in Cognitive Science, 7, 391-396.

Swenson, L. S. (1970). The Michelson-Morley-Miller experiments before and after 1905. Journal for the History of Astronomy, 1, 56-78.

Thagard, P. (2010). The brain and the meaning of life. Princeton: Princeton University Press.

Thagard, P. (2014). Thought experiments considered harmful. Perspectives on Science, 22, 288305.

Walton, K. (1990). Mimesis as make-believe: On the foundations of the representational arts. Cambridge: Harvard University Press.

Wansing, H. (2017). Remarks on the logic of imagination. A step towards understanding doxastic control through imagination. Synthese, 194, 2843-2861.

Weisberg, D. S., Sobel, D. M., Goodstein, J., \& Bloom, P. (2013). Young children are realityprone when thinking about stories. Journal of Cognition and Culture, 13, 383-407. 
Westra, E. (2017). Spontaneous mindreading: A problem for the two-systems account. Synthese, 194, 4559-4581.

Williamson, T. (2016). Knowing by imagining. In A. Kind \& P. Kung (Eds.), Knowledge through imagination (pp. 113-123). Oxford: Oxford University Press.

Wiltsche, H. A. (2018). Phenomenology and thought experiments: Thought experiments as anticipation pumps. In M. T. Stuart, et al. (Eds.), The Routledge companion to thought experiments (pp. 342- 366). London: Routledge.

Yablo, S. (1993). Is conceivability a guide to possibility? Philosophy and Phenomenological Research, 53, 1-42.

Yonelinas, A. P., Kroll, N. E. A., Quamme, J. R., Lazzara, M. M., Sauve, M. J., Widaman, K. F., et al. (2002). Effects of extensive temporal lobe damage or mild hypoxia on recollection and familiarity. Nature Neuroscience, 5, 1236-1241. 